\title{
MODELAGEM POR MEIO DE DADOS INFORMACIONAIS UTILIZANDO ALGORITMOS EVOLUTIVOS 1
}

\author{
MODELLING USING DATA OBTAINED FROM EVOLUTIONARY \\ ALGORITHMS
}

\author{
Jarryer Andrade De Martino \\ Centro Universitário Barão de Mauá, CBM \\ jarryermartino@gmail.com
}

\begin{abstract}
Resumo
O sistema generativo de projeto é potencializado ao incorporar métodos evolutivos em sua estrutura, transformando o processo de projeto em uma busca exaustiva por soluções que melhor se adaptam a um dado problema. O método é inspirado no mecanismo evolutivo presente na Natureza, apresentando como principais características a geração de diversidade de indivíduos e a seleção dos melhores adaptados, ocorrendo um processo de negociação por meio da integração e interação entre o grande número de espécies e das suas variações. Este método é capaz de gerar diversas soluções, produzindo uma grande quantidade de dados que precisam ser avaliados e selecionados. Assim, este artigo tem como objetivo apresentar um experimento de modelagem geométrica de um edifício por meio de dados informacionais gerenciados por um mecanismo evolutivo, sendo utilizada a manipulação dos seus componentes para favorecer e potencializar as características exploratórias e investigativas do processo de projeto.
\end{abstract}

Palavras-chave: Algoritmos evolutivos. Método de projeto. Modelagem de informação.

\begin{abstract}
The performance of generative design system could be enhanced by incorporating evolutionary methods in its structure, transforming the design process in an exhaustive search to find the best solution. The method is inspired by evolutionary mechanism of nature and its goal is to generate diversity and selection the best solution. There is a negotiation process among the different species of the systems. This method generates a variety of solutions, producing a large amount of data that must be evaluated and selected. Thus, this article aims to present a geometric modeling experiment of a building by data managed by an evolutionary mechanism. Their components are manipulated to promote and enhance the exploratory and investigative features of the design process.
\end{abstract}

Keywords: Evolutionary algorithms. Design method. Information modeling.

\section{INTRODUÇÃO}

O sistema generativo consiste de um conjunto de instruções operativas, ou seja, uma definição algorítmica responsável pela geração de soluções potenciais, apresentando uma estruturação lógica capaz de solucionar um determinado problema em diferentes situações, gerando um complexo espaço de soluções (TERZIDIS, 2009). Isso resulta em um método

\footnotetext{
${ }^{1}$ MARTINO, J. A. Modelagem por meio de dados informacionais utilizando algoritmos evolutivos. In: ENCONTRO BRASILEIRO DE TECNOLOGIA DE INFORMAÇÃO E COMUNICAÇÃO NA CONSTRUÇÃO, 7., 2015 , Recife.

Anais... Porto Alegre: ANTAC, 2015.
} 
indireto de projeto, uma vez que o projetista não interage diretamente com o objeto projetado, mas sim na definição e estruturação do sistema generativo (FISCHER; HERR, 2004). Segundo Mitchell (1975), esse tipo de sistema pode ser classificado como simbólico, devido à representação das soluções por meio da significação de símbolos como palavras, números e operadores matemáticos, resultando em sentenças ou formulações. A execução e solução das funções lógicas e aritméticas como a substituição, concatenação, adição, subtração, multiplicação, união e intersecção são responsáveis pela mudança de estado desse sistema.

Esse método possibilita gerar famílias ou gerações inteiras de um projeto a partir da permutação exaustiva de seus elementos, apresentando como limite para o espaço de soluções os intervalos definidos previamente para as variáreis e parâmetros que compõem o sistema. A implementação computacional desse método potencializa o processo, oferecendo alta capacidade de processamento para a realização das operações, produzindo um amplo espaço de soluções em um reduzido período de tempo. Dessa forma, é de grande importância a incorporação de um mecanismo de busca inteligente capaz de controlar e avaliar as soluções, permitindo o controle sobre o processo de projeto e o refinamento dos resultados (JONES, 1992, p.54), selecionando as que melhor satisfazem o problema.

Algumas dessas estratégias implementadas computacionalmente são os algoritmos evolutivos, que correspondem a um conjunto de métodos de busca, otimização, aprendizagem e modelagem de dados inspirados na evolução biológica baseada na Teoria da Evolução de Darwin (BENTLEY, 1999). A diversidade, a hereditariedade e a seleção dos indivíduos melhores adaptados ao meio são as principais características dessa teoria, sendo reproduzidos no ambiente computacional por meio de mecanismos evolutivos que também são estruturados algoritmicamente, permitindo simular a evolução das soluções. Esses algoritmos são utilizados para a realização de uma busca inteligente em um espaço de soluções muito grande e onde há a necessidade de analisar multicritérios, sendo obtida como melhor solução aquela que consegue satisfazer simultaneamente todas as variáveis envolvidas no sistema. Dessa forma, a adoção dos algoritmos evolutivos permite ao projetista extrapolar a simples inspiração nas formas e nas estruturas da Natureza, e passa a entender a lógica intrínseca que está presente no processo morfológico natural (FRAZER, 1995). O mecanismo evolutivo incorpora métodos probabilísticos na sua estrutura para a classificação e seleção das melhores soluções geradas pelo sistema (MITCHELL, 1999; LINDEN, 2008), sendo utilizadas como referência as informações obtidas no próprio modelo geométrico. Essas informações podem ser armazenadas, manipuladas e analisadas com a ajuda de recursos como gráficos, tabelas, matrizes e outros tipos de formatação, auxiliando o projetista na interpretação e gestão da informação, e consequentemente, refletindo na modelagem.

Este artigo apresenta um experimento sobre modelagem geométrica de um edifício por meio de dados informacionais gerenciados por um mecanismo evolutivo, sendo utilizada a manipulação dos seus componentes para favorecer e potencializar as características exploratórias e investigativas do processo de projeto. Antes disso, é importante apresentar e definir os componentes relacionados ao mecanismo evolutivo, a sua estrutura básica e o seu funcionamento, revelando os procedimentos responsáveis pela geração e manipulação dos dados informacionais.

\section{MÉTODO EVOLUTIVO E OS SEUS COMPONENTES}

O principal objetivo para a utilização dos algoritmos evolutivos é a busca por soluções para problemas que possuem mais de um critério de avaliação e diferentes objetivos a serem atingidos (FLOREANO; MATTIUSSI, 2008), gerando um grande espaço de soluções composto por diversas possibilidades de soluções. Essa situação pode ser denominada 
como trade-offs, ou seja, onde há um conflito de escolha, de maneira que ao favorecer o ganho de um dos objetivos pode sacrificar outro, existindo assim uma "relação de compromisso" entre os diferentes objetivos. Esses algoritmos apresentam como principais características a reprodução com herança genética, a variação aleatória em uma população de indivíduos e a aplicação de seleção natural para gerar as próximas gerações. A sua estrutura básica é constituída por populações de indivíduos (representando as possíveis soluções de um problema), operadores de diversidade (responsáveis pela diversificação dos indivíduos) e funções de aptidão dos indivíduos (que verificam o grau de satisfação das soluções obtidas).

Uma das principais dificuldades encontradas no processo de implementação desses algoritmos evolutivos como um método de projeto está relacionada com a representação do elemento arquitetônico, do edifício, de uma malha urbana ou qualquer outro elemento passível de ser projetado. Para esses diferentes tipos de projetos, a denominação "indivíduo" será adotada como forma de generalização e padronização durante o texto, correspondendo inclusive ao termo utilizado na computação evolutiva. A representação assume um papel fundamental em todo o processo, pois a adoção de uma codificação desfavorável pode gerar indivíduos infactíveis quando ocorrer a aplicação dos operadores de diversidade durante o processo de execução do algoritmo (BENTLEY, 1999). Assim, o indivíduo é representado abstratamente através de uma codificação, utilizando como referência o modelo cromossômico. Dessa forma, cada característica do indivíduo é definida por um gene, e o conjunto deles compõe um cromossomo responsável por representar o indivíduo como um todo, a exemplo da codificação do ser humano através do DNA. Outra possibilidade é a representação sem a codificação, sendo utilizados os números inteiros para representar diretamente as características do indivíduo, evitando o processo de mapeamento e consequentemente a constante necessidade de codificação e decodificação. Assim, em um processo de projeto, as características de um indivíduo podem corresponder diretamente ao seu valor de dimensão e localização espacial como exemplificado na Figura 1.

Figura 1 - Exemplo de codificação de um indivíduo, representação cromossômica

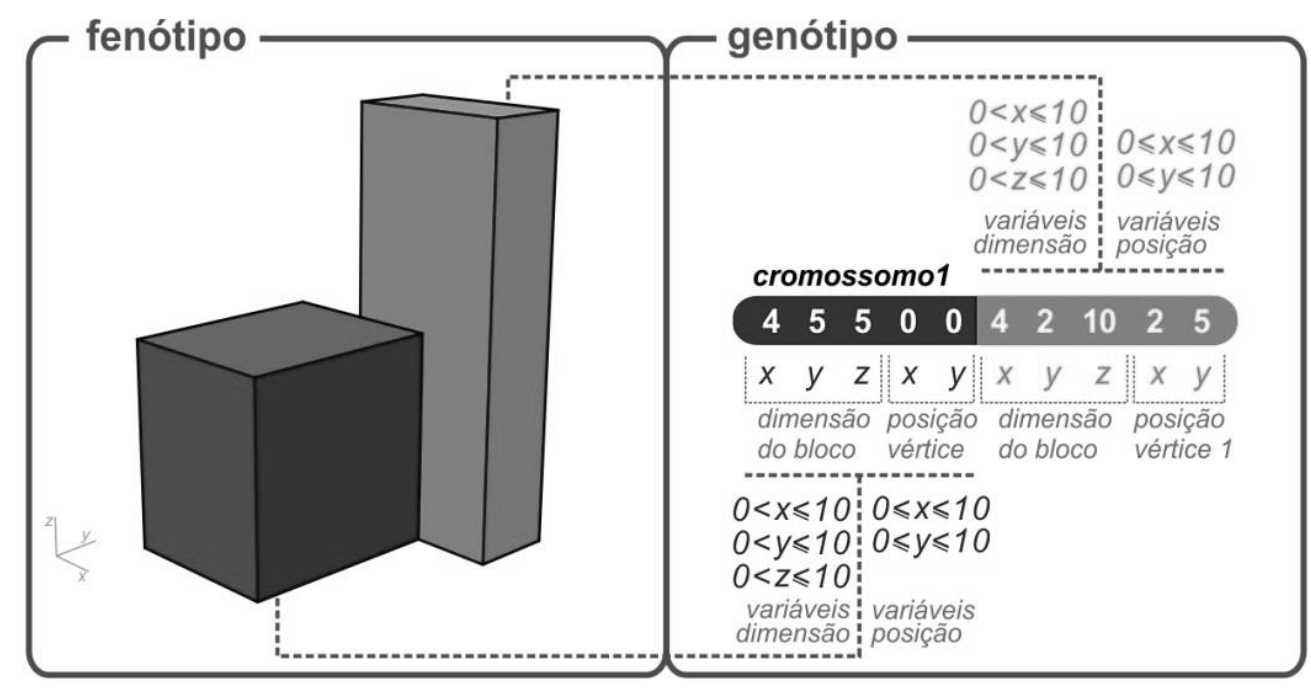

Fonte: elaborado pelo autor.

O indivíduo deve ser constituído por um ou mais componentes cujas características são representadas por valores numéricos variando entre um mínimo e máximo. Além disso, o indivíduo também é definido pelos padrões estruturais que os compõem, fornecendo um conhecimento geral sobre o seu potencial configurativo caracterizado por atributos 
geométricos (OXMAN, OXMAN; 2010). Dessa forma, cada valor adotado para as características do indivíduo produzirá um efeito específico na sua estrutura, gerando soluções distintas (Figura 2).

Figura 2 - Diferentes indivíduos obtidos a partir da variação dos parâmetros

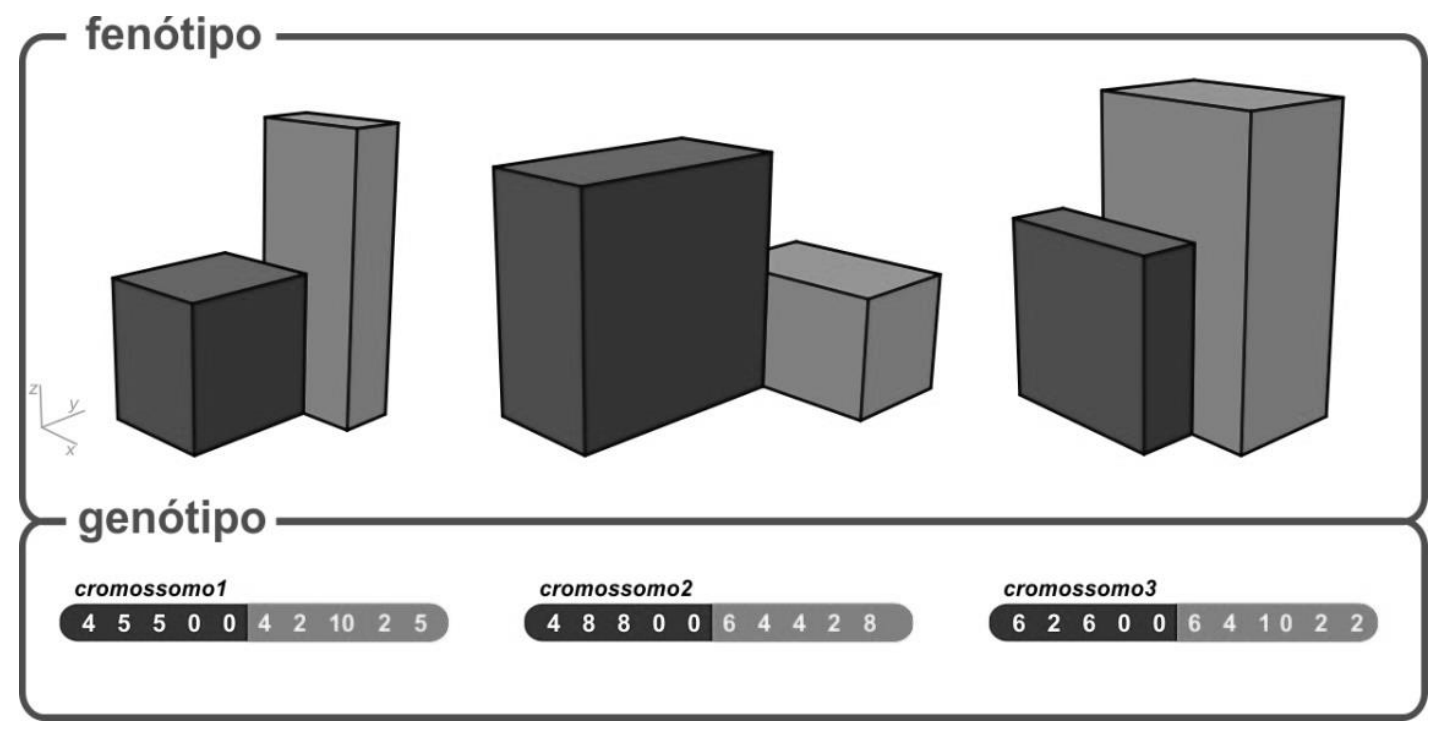

Fonte: elaborado pelo autor.

A população inicial do algoritmo evolutivo é composta por indivíduos escolhidos randomicamente entre as diferentes possibilidades de configuração, sendo o número de indivíduos definido pelo projetista. A partir dessa população, o processo é iniciado com a avaliação de cada indivíduo, recebendo a maior nota aqueles que possuírem o maior grau de satisfação simultânea para os diferentes parâmetros adotados previamente como referência. Estes parâmetros são embasados em informações de caráter técnico ou pessoal (conforme a decisão do projetista diante do seu repertório intelectual - exemplo, relações geométricas) e que podem ser representados matematicamente. Essa avaliação ocorre através da função de avaliação (fitness function), que deverá conter na sua formulação as restrições e condições funcionais necessárias às características desejadas no indivíduo. Dessa forma, após a aplicação da função de avaliação, os indivíduos recebem uma nota correspondente ao seu grau de atendimento às restrições, sendo esses valores utilizados para comparação, classificação e seleção daqueles mais aptos para compor a próxima geração.

A mutação e a recombinação são os operadores de diversidade, responsáveis efetivamente para a manutenção da diversidade, condição necessária para que ocorra a competição entre os indivíduos durante o processo evolutivo. A mutação irá modificar aleatoriamente (comportamento definido algoritmicamente) um gene do cromossomo de um indivíduo, resultando em uma alteração fenotípica, ou seja, um indivíduo com característica diferente do original (Figura 3). A recombinação corresponde à troca de partes entre dois ou mais cromossomos e está relacionada com o processo de cruzamento. Embora esse processo contribua para a variedade, diferentemente da mutação, ele manterá certo grau de familiaridade entre os indivíduos, uma vez que são realizadas apenas trocas entre pedaços dos cromossomos, sendo transferidas as características de um indivíduo para outro (Figura $3)$. 
Figura 3 - Geração de um novo indivíduo a partir da mutação e recombinação

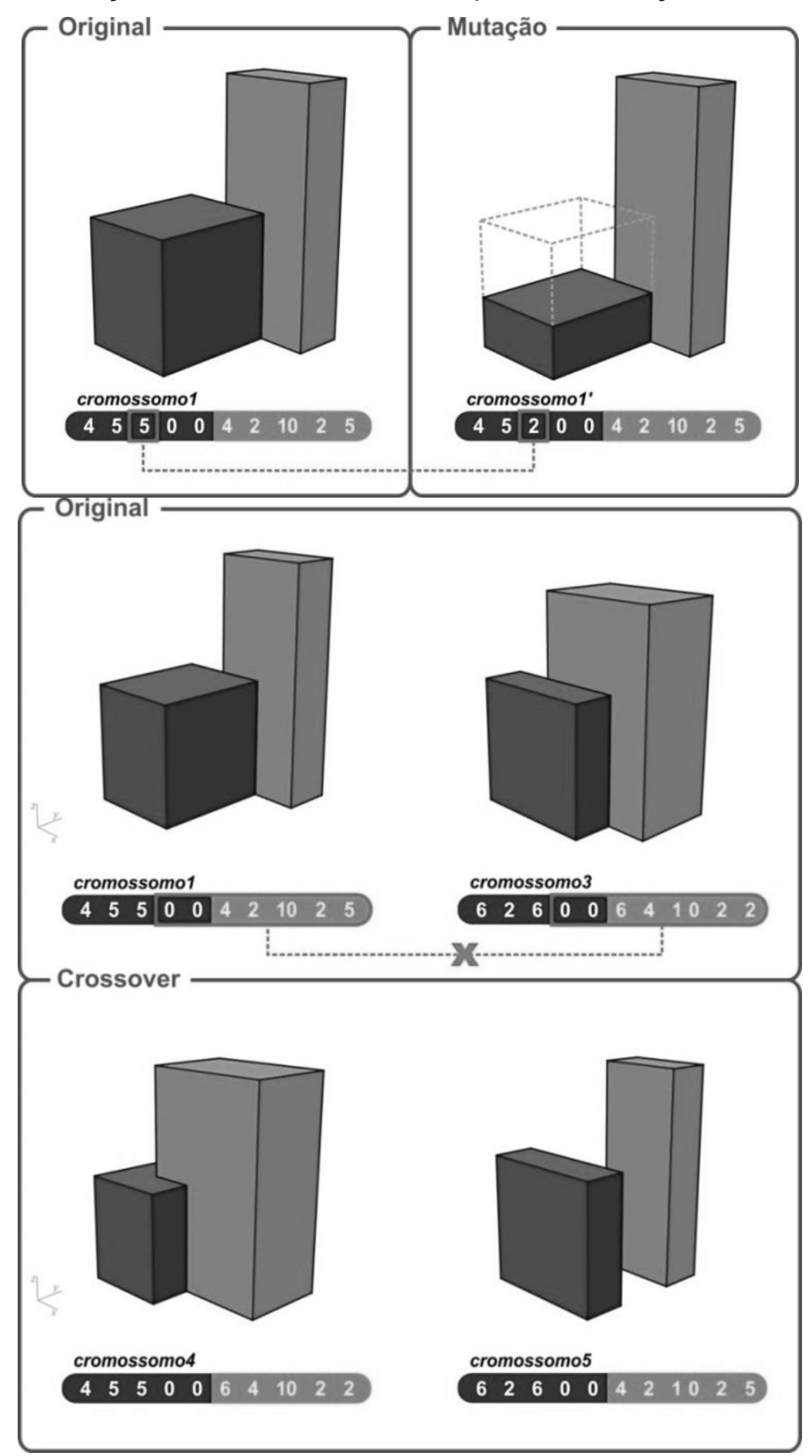

Fonte: elaborado pelo autor.

Após a aplicação dos operadores de diversidade, os novos indivíduos serão avaliados, classificados e selecionados por meio de métodos probabilísticos, compondo a próxima geração e completando um ciclo denominado iteração. Este ciclo é repetido várias vezes até obter o melhor indivíduo, ou quando atingir um tempo pré-determinado, ou um número de gerações definido previamente pelo projetista (BENTLEY, 1999; TIERNEY, 2007; HENSEL; MENGES; WEINSTOCK, 2010) (Figura 4). 
Figura 4 - Estrutura basica do algoritmo evolutivo

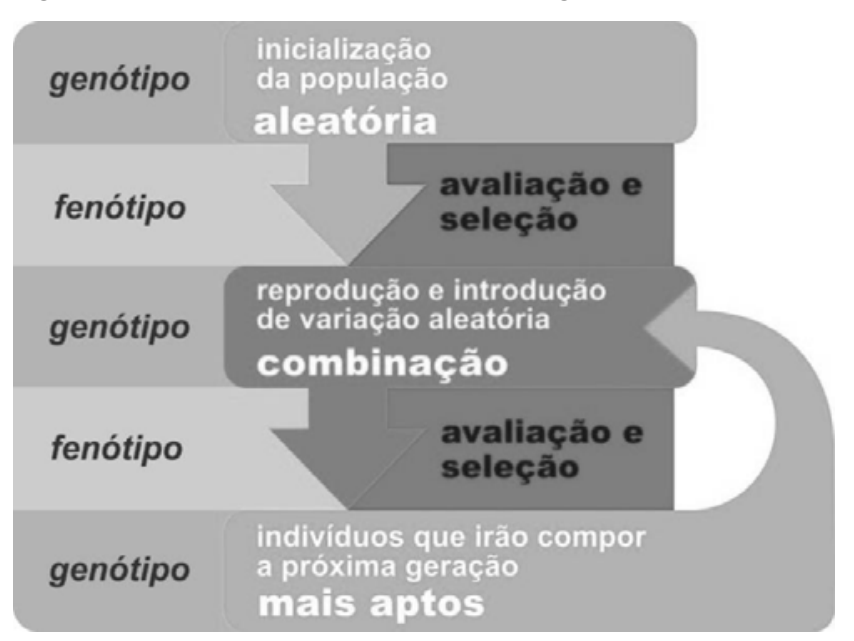

Fonte: elaborado pelo autor.

A partir desse panorama sobre o funcionamento do método evolutivo e dos seus componentes é possível verificar a utilização dos dados informacionais como matéria prima para o desenvolvimento de todo o sistema. Podem ser encontrados neste método dois tipos de dados: os responsáveis pela representação das características do objeto a ser projetado e os dados resultantes do processo de avaliação e seleção das soluções. A adoção de números inteiros para a representação das características do objeto, a definição da função de avaliação por meio de formulações e a adoção de métodos probabilísticos para a classificação e seleção das melhores soluções contribuem para a construção de um sistema inspirado na modelagem matemática. Dessa forma, a matéria prima utilizada nesse sistema permite a adoção de recursos, como gráficos e tabelas, capazes de auxiliarem na visualização e avaliação das informações sobre os resultados e o comportamento do sistema generativo. Esses recursos conferem ao projetista melhores condições para a redefinição das suas estratégias projetuais, possibilitando a execução de diferentes experimentos, potencializando a característica exploratória e investigativa do processo de projeto.

O estudo de projeto apresentado na próxima seção exemplifica esse processo, sendo realizados seis experimentos com diferentes configurações para o sistema generativo evolutivo. Os diferentes experimentos geraram informações que auxiliaram na redefinição da configuração do mecanismo evolutivo, favorecendo o processo de busca pelas soluções mais favoráveis e o melhor entendimento sobre o próprio mecanismo.

\section{MODELANDO COM DADOS INFORMACIONAIS: EXPERIÊNCIA PRÁTICA}

O objetivo deste experimento é apresentar a modelagem volumétrica de um edifício por meio da gestão de dados obtidos a partir do próprio modelo geométrico. O sistema generativo evolutivo foi escolhido devido a sua capacidade de gerenciar e negociar as diferentes variáveis conflitantes envolvidas na solução de um problema, atendendo simultaneamente os multicritérios envolvidos no processo. O partido de projeto definido para este experimento foi a busca pela integração dos seguintes critérios: (1) a implantação do edifício no lote considerando as diferentes zonas de ocupação que limitam a sua altura mínima e máxima, (2) a maximização da área de ocupação no lote, (3) a maximização do volume do edifício e (4) a minimização do seu perímetro. O modelo paramétrico do edifício foi constituido por seis módulos independentes que se deslocam livremente pelo lote com dimensão de $20 \mathrm{~m}$ de largura por $50 \mathrm{~m}$ de comprimento (Figura 5). Cada módulo possui a forma de um quadrado com dimensão de $10 \mathrm{~m}$ com altura variando entre $8 \mathrm{~m}$ e $40 \mathrm{~m}$ 
conforme a sua posição no lote. Assim, o lote foi zoneado de maneira a apresentar alturas específicas para os módulos de acordo com cada zona, definindo uma volumetria escalonada (Figura 5). Dessa forma, a intenção do projetista é obter uma volumetria com a maior ocupação possível para o lote, por meio da distrituição desses módulos, conciliando a maximização do volume (respeitando o zoneamento) e o menor índice par ao perímetro.

Figura 5 - Zoneamento do lote para a definição das alturas dos módulos

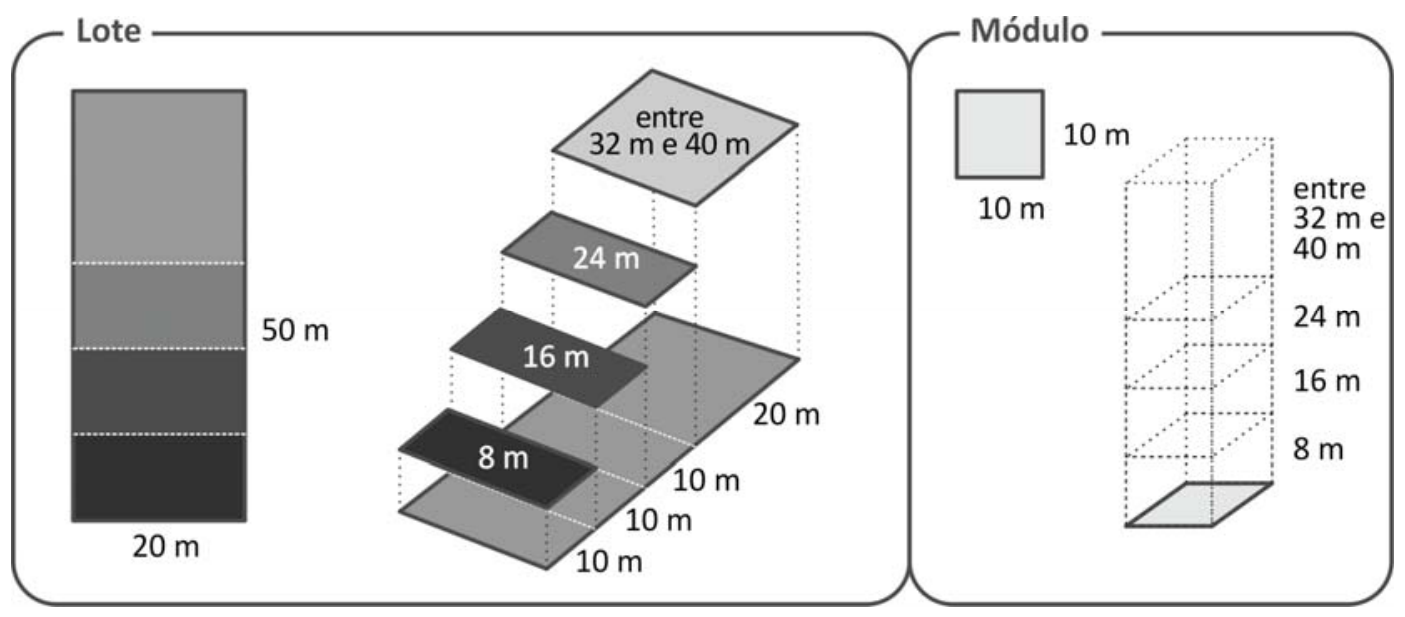

Fonte: elaborado pelo autor.

A definição algorítmica para o projeto foi estruturada em três blocos (Figura 6), o primeiro referente aos elementos definidores da forma e as suas relações paramétricas ("definições formais e relacionais"), o segundo relacionado à obtenção de dados e a fomulação matemática dos critérios de avaliação dos indivíduos, e o terceiro bloco é responsável pela execução do algoritmo evolutivo. O sistema generativo evolutivo foi implementado computacionalmente utilizando o plugin Grasshopper $₫$ integrado ao programa Rhinoceros ${ }^{\circledR}$ 5.0, que permite a estruturação do código a partir de componentes visuais (Figura 6).

Figura 6 - Estruturação dos códigos

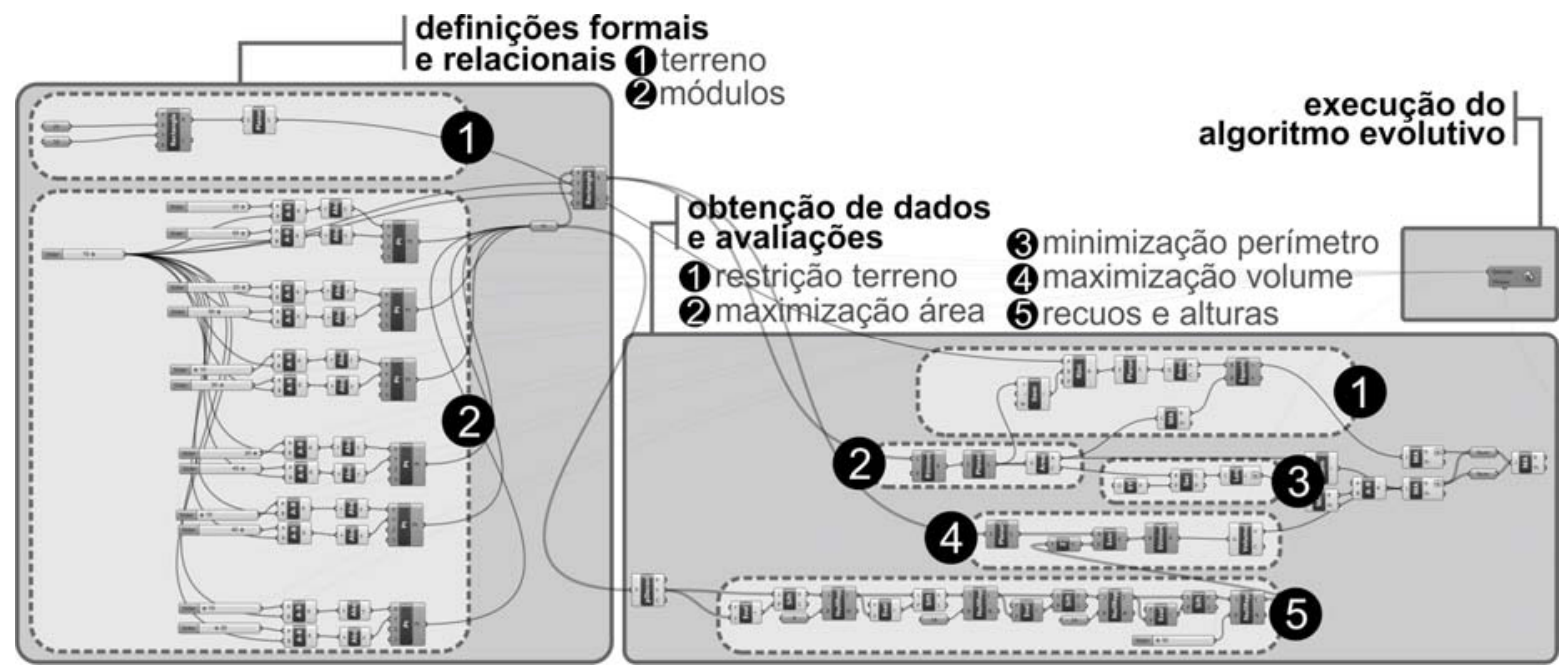

Fonte: elaborado pelo autor.

Embora os três blocos funcionem de maneira integrada, cada um deles gera dados informacionais distintos, assumindo funções específicas no sistema. No bloco "definições formais e relacionais" são definidas as dimensões dos módulos que compõem a volumetria 
do edifício (o valor mínimo e máximo para largura, comprimento e altura), as coordenadas referentes ao posicionamento dos módulos no lote e as relações estabelecidas entre essas variáveis (o posicionamento do módulo dentro do lote precisa ser coerente com a sua dimensão). Estas informações definidas por valores numéricos que representam as características de cada indivíduo, compondo assim, os genes do seu cromossomo. No bloco "obtenção de dados e avaliações" são definidas formulações matemáticas responsáveis pelo cálculo da área, do volume e do perímetro do edifício, assim como a área de intersecção entre as superfícies dos módulos com o terreno, viabilizando apenas as soluções que apresentam um resultado não nulo para essa relação. Os valores numéricos obtidos neste último bloco são testados matematicamente por meio de funções que expressam os critérios definidos pelo projetista (função de avaliação ou fitness function), permitindo verificar se eles estão dentro dos limites adotados como referência. Estes valores são posteriormente somados para a geração de um índice denominado valor de fitness ou aptidão, sendo a informação responsável pela representação do indivíduo no processo de classificação e seleção. O bloco "execução do algoritmo evolutivo" é responsável pela criação de diversidade nas soluções, realizando o cruzamento dos indivíduos, a aplicação de mutação, a avaliação e seleção das soluções mais aptas.

O componente Galapagos do plugin Grasshopper® oferece a implementação simplificada do mecanismo evolutivo, sendo necessária apenas a configuração de alguns parâmetros. Este componente articulou as informações entre os dois primeiros blocos, ou seja, associou o cromossomo de cada indivíduo definido no bloco "definições formais e relacionais" (cromossomo da solução) ao valor de fitness obtido no bloco "obtenção de dados e avaliações". Durante a sua execução, o componente cria automaticamente uma base de dados contendo todos os cromossomos e valores de aptidão dos indivíduos gerados pelo sistema, possibilitando a classificação e seleção dos que melhor satisfazem o aspecto definido para o algoritmo, sendo neste experimento adotada a maximização dos valores. Dessa forma, o perímetro exigiu uma codificação diferenciada, pois era a única situação de minimização do valor, sendo adotado um valor fixo de referência para a subtração do valor do perímetro da solução avaliada, de maneira que, quanto maior fosse o valor da diferença, menor seria o perímetro da solução. Isso permitiu colocar todos os critérios na condição de maximização dos seus valores.

O método probabilístico presente na estrutura do código evolutivo e embutido no componente Galapagos identificou, classificou e selecionou automaticamente os maiores valores de fitness, recuperando os cromossomos associados a esses valores para dar sequência ao processo evolutivo. Assim, o conjunto de genes, ou seja, de dados informacionais favoráveis à obtenção de bons valores de aptidão se mantiveram no processo, ou foram utilizados para a composição de novos indivíduos. Dessa forma, é possível perceber como todo processo se desenvolve considerando apenas as informações geradas pelo próprio modelo, sendo manipulados os valores numéricos definidos para representarem simbolicamente o modelo geométrico.

A facilidade de manipulação do sistema generativo permitiu a geração de diferentes experimentos com apenas a redefinição da configuração de dois parâmetros relacionados à geração de diversidade de indivíduos, o Initial Boost e o Inbreeding, sendo realizados seis experimentos (Quadro 1). O primeiro é um fator responsável pela multiplicação do número de indivíduos que constituem a primeira geração produzida pelo algoritmo evolutivo, e o segundo está relacionado com o critério de seleção para a formação dos pares a serem cruzados (maior ou menor semelhança entre os indivíduos), sendo esse parâmetro definido em porcentagem. Os outros parâmetros do mecanismo evolutivo se mantiveram constantes nos seis experimentos, como a maximização do valor de aptidão, a finalização da execução do algoritmo com a estagnação de cinquenta gerações sucessivas ou até completar cem gerações, as populações compostas por trinta indivíduos (com excesão a primeira) e a taxa 
de $5 \%$ de permanência dos melhores indivíduos entre as gerações. $O$ valor padrão para o Initial Boost é de duas vezes, mas segundo o desenvolvedor do plugin, os fatores cinco e dez vezes podem ajudar a obter soluções mais diversificadas. O Inbreeding foi testado utilizando o porcentual padrão de $75 \%$ e a opção de $50 \%$, pressupondo que o cruzamento entre indivíduos com menor grau de semelhança poderia gerar maior diverisade e ajudar no processo evolutivo a encontrar as soluções mais aptas. Dessa forma, os experimentos foram realizados considerando a seguinte configuração para o Initial boost e Inbreeding:

Quadro 1 - Valores adotados ara o Initial Boost e Inbreeding

\begin{tabular}{|l|c|c|c|c|c|c|}
\hline & EX1 & EX2 & EX3 & EX4 & EX5 & EX6 \\
\hline Initial Boost & $2 \mathrm{x}$ & $2 \mathrm{x}$ & $5 \mathrm{x}$ & $10 \mathrm{x}$ & $10 \mathrm{x}$ & $5 \mathrm{x}$ \\
\hline Inbreeding & $75 \%$ & $50 \%$ & $75 \%$ & $75 \%$ & $50 \%$ & $50 \%$ \\
\hline
\end{tabular}

Fonte: elaborado pelo autor.

A figura a seguir apresenta a evolução dos valores de aptidão (FIT1, FIT2 e FIT3) das três melhores soluções obtidas a cada dez gerações dos seis experimentos. A visualização desses dados possibilitou compreender melhor o mecanismo evolutivo, permitindo analisar o seu comportamento diante da mudança dos parâmetros Initial Boost e Inbreeding.

Figura 7 - Valores adotados para o Initial Boost e Inbreeding

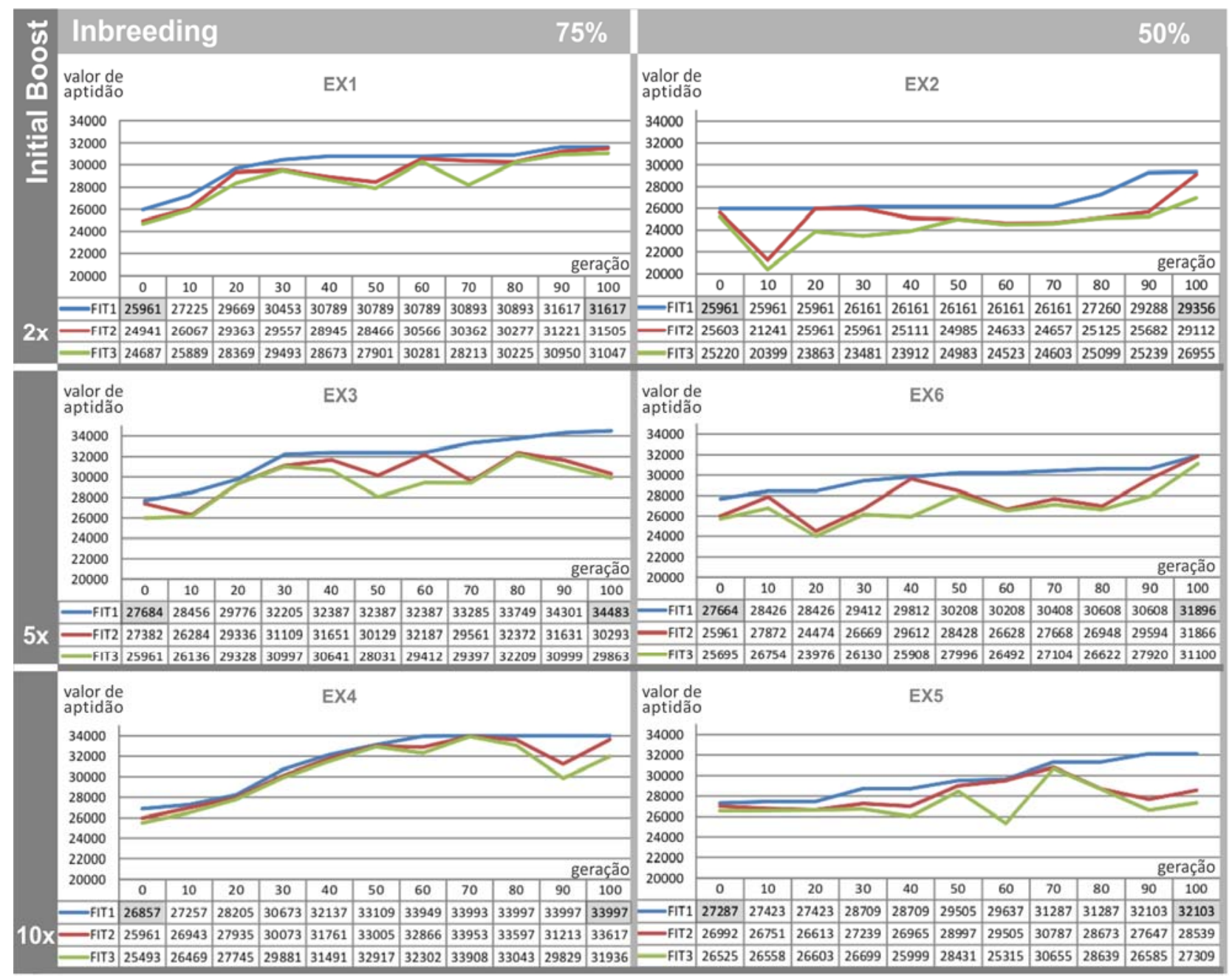

Fonte: elaborado pelo autor. 
A comparação entre os reultados obtidos com o fator de Inbreeding $75 \%$ e o de $50 \%$ permite constatar que o cruzamento entre indivíduos com menor grau de semelhança dificulta encontrar soluções com o maior valor para a aptidão. Isso ocorre porque os pares de indivíduos selecionados para serem cruzados possuem maior grau de diferenciação entre si, sendo gerada constantemente uma variedade genética que dificulta a constância das estruturas genéticas favoráveis às soluções mais aptas. Embora a diversidade genética seja favorável, os exprimentos revelaram que a permanência e a constância de certas estruturas são necessárias para que exista a hereditariedade e a evolução da espécie. Por isso, os experimentos EX2, EX6 e EX5, que utilizaram o valor de Inbreeding igual a $50 \%$ apresentaram resultados inferiores para os valores de aptidão aos dos experimentos EX1, EX3 e EX4 respectivamente, onde foi empregada a taxa de 75\% (Figura 7). Ou seja, o maior valor para a taxa de Inbreeding promoveu o cruzamento entre pares de indivíduos com o maior grau de semelhança, fazendo com que as estruturas genéticas favoráveis às soluções mais aptas fossem transmitidas às gerações subsequentes. Assim, ocorreu a formação de uma espécie (especiação) que foi aprimorada constantemente por meio de pequenos ajustes (recombinação e mutação) ao longo da execução do algoritmo evolutivo, mantendo a estrutura genética favorável. Isso pode ser justificado pela Teoria Evolucionista, que define a evolução como um processo gradativo, e não ocorrendo em grandes saltos. A comparação entre os resultados do EX1 e EX3 revela um aumento no valor de aptidão de 9\% no primeiro indivíduo (FIT1) da última geração, ocorrendo a diminuição nos outros (FIT2 e FIT3). Já no EX2 e EX6 ocorreu o aumento de 15\% no terceiro indivíduo (FIT3) da última geração, sendo que os primeiros (FIT1 e FIT2) tiveram o aumento de aproximadamente $9 \%$. Embora a análise em porcentagem dos resultados pareça favorável aos experimentos EX2 e EX6, com os valores de aptidão de 29356 e 31896 respectivamente (Figura 7), é importante destacar que o EX1 e EX3 alcançaram os valores maiores, 31617 e 34483 respectivamente, favorecendo os experimentos com $75 \%$ de Inbreeding.

A diversidade genética gerada pelo Initial Boost, a princípio, deveria contribuir para a potencialização do algoritmo evolutivo, uma vez que ele aumenta a quantidade de indivíduos que compõem a população da primeira geração. Isso auxiliaria na obtenção de indivíduos com maior valor de aptidão, já que aumentaria a probabilidade de serem geradas e encontradas mais opções de soluções com melhor valor de aptidão. Mas ao analisar os dados dos experimentos foi possível verificar que o ganho obtido não foi expressivo, apresentando inclusive resultado negativo em alguns experimentos, como no EX3. Dessa forma, é possível perceber que a quantidade de indivíduos na primeira geração não garante a obtenção de melhores valores para a aptidão, uma vez que a quantidade não está diretamente relacionada à qualidade dos indivíduos. Dessa forma, a quantidade de indivíduos na primeira geração não possui relação direta com a melhor aptidão dos indivíduos, apenas aumenta probabilisticamente as chances de obtê-las. Assim, diante da análise dos dados, é possível afirmar que a variação na taxa de Inbreeding contribui mais expressivamente para a obtenção do melhor valor de aptidão, do que o fator Initial Boost.

Diante dos seis experimentos, a melhor solução é aquela que apresenta o maior valor de aptidão, uma vez que a característica adotada para este algoritmo evolutivo foi o de maximização dos valores. Isso justifica a escolha da solução FIT1 da última geração do EX3 (Figura 8). 
Figura 8 - Modelos geométricos obtidos nos experimentos

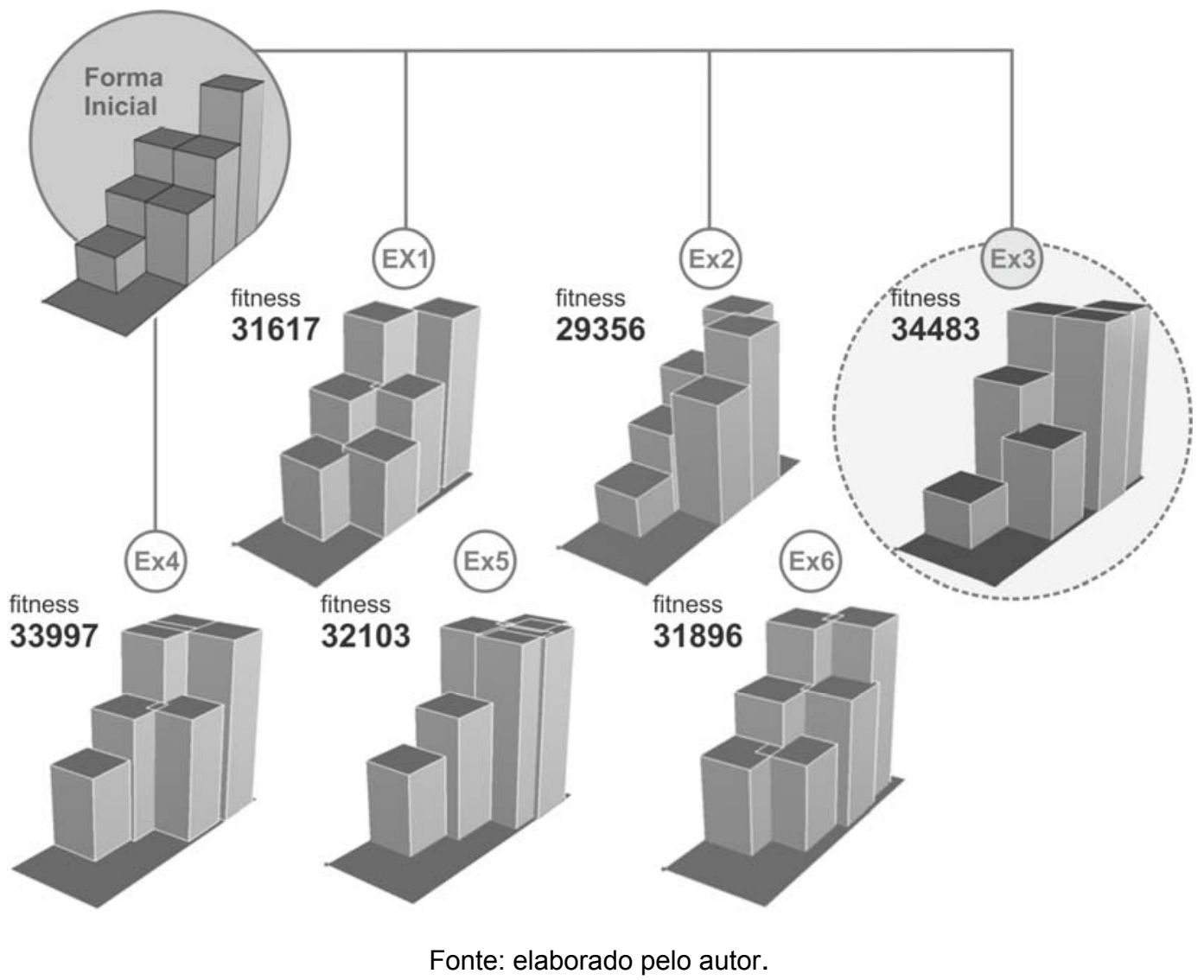

\section{CONCLUSÃO}

A adoção de um sistema generativo de projeto implementado computacionalmente revela o dado informacional como um elemento fundamental em todo o processo, o caráter simbólico do sistema exige uma representação que vai desde a codificação do objeto a ser projetado até a formulação matemática dos critérios que satisfazem a intenção do projetista. $O$ projetista manipula valores numéricos e funções matemáticas para criar modelos matemáticos responsáveis pela estruturação do sistema, utiliza os dados informacionais como matéria prima durante o processo de modelagem. A análise comparativa entre dados e a utilização de gráficos foram transformadas em instrumentos durante o processo de concepção do projeto, não se restringindo à fase intermediária ou final do processo de projeto. O projetista adota a gestão dos dados informacionais para a obtenção de uma solução formal, que ao manipular e modelar essas informações irá obter como consequência o resultado expresso em um modelo geométrico.

\section{AGRADECIMENTOS}

O autor agradece à FAPESP pela concessão da bolsa de doutorado, processo 2012/181127, e à Profa. Dra. Gabriela Celani pela orientação durante o desenvolvimento da tese, do qual este artigo faz parte. 


\section{REFERÊNCIAS}

BENTLEY, P. J. Evolutionary Design by Computers. San Francisco: Morgan Kaufmann Publishers Inc, 1999.

FISCHER, T.; HERR, C. M. Teaching Generative Design. In: SODDU, C. Proceedings of the 4th International Generative Art Conference. Disponível em: <http://www.generativeart.com> Acessado em: 10 abr. 2014.

FLOREANO, D.; MATTIUSSI, C. Bio-inspired artificial intelligence: theories, methods, and technologies. Cambridge: The MIT Press, 2008.

FRAZER, J. An evolutionary architecture. London: Architectural Association, 1995.

HENSEL, M.; MENGES, A.; WEINSTOCK, M. Emergent Technologies and design: towards a biological paradigm for architecture. Oxon: Routledge, 2010.

JONES, J. C. Design methods / John Chris Jones; with prefaces by C. Thomas Mitchell and Timothy Emlyn Jones. 2.ed. New York: Wiley, 1992.

LINDEN, R. Algoritmos genéticos. 2.ed. Rio de Janeiro: Brasport, 2008.

MITCHELL, M. An introduction to genetic algorithms. Cambridge: The MIT Press, 1999.

MITCHELL, W. J. The theoretical foundation of computer-aided architectural design. Environment and Planning B. v.2, 1975, p.127-150.

OXMAN, R.; OXMAN, R. New structuralism: design, engineering and architectural technologies. Architectural Design, v. 80, n. 4, p14-23, jul./ago. 2010.

TERZIDIS, K. Algorithmic architecture. Oxford: Elsevier, 2009.

TIERNEY, T. Abstract space: beneath the media surface. Oxon: Taylor \& Francis, 2007. 